\title{
Bio-politics and the promotion of traditional herbal medicine in Vietnam
}

Wahlberg, Ayo

Published in:

Health:

DOI:

$10.1177 / 1363459306061784$

Publication date:

2006

Document version

Early version, also known as pre-print

Citation for published version (APA):

Wahlberg, A. (2006). Bio-politics and the promotion of traditional herbal medicine in Vietnam. Health:; 10(2), 123-147. https://doi.org/10.1177/1363459306061784 


\title{
Bio-politics and the promotion of traditional herbal medicine in Vietnam
}

\author{
Ayo Wahlberg \\ BIOS Centre, London School of Economics and Political Science, United Kingdom
}

\begin{abstract}
It is often suggested that during the past fifty years, Vietnam has experienced a traditional medicine 'revival' that can be traced back to late President Ho Chi Minh's 1955 appeal "to study means of uniting the effects of oriental remedies with those of Europe". In this paper, I demonstrate how traditional herbal medicine came to be recruited as an important component of national efforts to safeguard and promote the public health of urban and rural populations in Vietnam. Importantly, this has entailed a rejection of a colonial bio-politics that sought to marginalise and even eradicate "quackery" and "sorcery" in favour of a postcolonial bio-politics that aims to promote the "responsible" and "appropriate" use of traditional herbal medicines. While the Vietnamese case bears many parallels to a number of other countries in this respect, notably China, Vietnam's ancient history of medicine, prolonged postcolonial isolation and far-reaching health delivery network have resulted in a unique public health strategy that encourages rural populations to become self-sufficient in the traditional herbal treatment of their most common illnesses.
\end{abstract}

\section{Key words}

Vietnam, traditional herbal medicine, bio-politics, quackery, sociology of traditional medicine

\section{Address}

BIOS Centre, London School of Economics, Houghton Street, London WC2A 2AE, UK. [Tel: +44 (0)20 7107 5251, fax: +44 (0)20 7955 7405, e-mail: a.j.wahlberg@lse.ac.uk]

\section{Acknowledgments}

Research for this article was made possible by an internationalisation grant from the Danish Research Agency as well as through the generous hospitality of Professor Trần Văn Sung, Director of the Institute of Chemistry, during my stays in Hanoi. A version of this article was first presented to colleagues at BIOS as well as at the Department of International Development Studies, Roskilde University. My thanks to the many people who have provided me with productive feedback, especially two anonymous referees whose comments have vastly improved this article.

\section{Author biography}

Ayo Wahlberg is a PhD Candidate at BIOS, a new centre for the study of bioscience, biomedicine, biotechnology and society under the Department of Sociology, London School of Economics and Political Science, United Kingdom. His comparative research is focused on aspects of regulation, validation and resistance in the indigenous traditional herbal medicine of Vietnam and the United Kingdom respectively. 
This paper has been accepted for publication in health: an interdisciplinary journal for the social study of health, illness and medicine, and the final (edited, revised and typeset) version of this paper will be published in health:; 10(2), April 2006 by Sage Publications Ltd, All rights reserved. (C) Sage Publications Ltd, 2006

\section{Introduction}

After decades of colonial efforts to eradicate, marginalise or limit the practice of what was often considered the 'quackery' or 'witchcraft' of 'backward' populations in especially Africa and Asia, the mid- $20^{\text {th }}$ century was to mark a turning point in the history of public health promotion in many so-called developing countries. The coinciding of a growing 'crisis of modern medicine' and the gradual demise of colonial rule left many newly independent nations with massive public health challenges, especially as regards those rural populations that had had little or no benefit from colonial health programmes. It was at this time that what has come to be known as 'traditional medicine' or TM began its transformation from a colonial evil that was to be routed out in the name of public health and progress into a postcolonial resource to be actively recruited in the quest to safeguard and improve the health of individuals and populations.

Not surprisingly, it is in China that a symbolic moment of this transformation might be placed. ${ }^{1}$ Following a lively debate within his own party as to whether or not the practice of traditional medicine should be wholly abolished, chairman Mao Zedong argued in a 1944 speech that:

"to rely solely on modern doctors is no solution. Of course modern doctors have advantages over doctors of the old type; but if they do not concern themselves with the suffering of the people, do not train doctors of the people, do not unite with the thousand and more doctors and veterinarians of the old type... then they will actually be helping the witchdoctors... There are two principles for the united front: the first is to unite and the second is to criticise, educate and transform" (cited in Hillier and Jewell 1983: 312-13). 

social study of health, illness and medicine, and the final (edited, revised and typeset) version of this paper will be published in health:; 10(2), April 2006 by Sage Publications Ltd, All rights reserved. (C) Sage Publications Ltd, 2006

Since then, countries as far apart as China, Ghana, Taiwan, Botswana, Mexico and Korea have all experienced a resurgence in the practice and use of their respective forms of traditional medicine (cf. Feierman, et al. 1992; Hong 2001; Kleinman 1980; Last, et al. 1986; Nigenda, et al. 2001; Taylor 2005; Tsey 1997). In these and many other countries increasing numbers of Academies, Departments, Associations, Hospitals and Institutes of Traditional Medicine have been established to advance research into and the development of medical practices based on their national cultural heritages. Increasing numbers of governments are now promoting the "safe", "effective" and "proper" practice and use of traditional medicine as an accessible and affordable means to providing 'healthcare for all', encouraged by the World Health Organization (World Health Organization 2002). What is more, this late $20^{\text {th }}$ century resurgence in the practice and use of traditional medicines in many newly independent 'developing countries' has been closely followed by a 'renaissance' in the practice and use of what are today known as 'complementary and alternative medicines' or CAM in an increasing number of industrialised countries (cf. Cant and Sharma 2000; Kelner and Wellman 2000; Saks 2003).

The case for a traditional medicine revival can certainly be made in Vietnam, and although it is China's longstanding medical traditions that have received most attention in the region (cf. Brown 1980; Kaptchuk 1983; Kleinman 1980; Lu and Needham 1980; Unschuld 1985), scholars of traditional medicine in Vietnam are keen to highlight that "far from being merely a copy of Chinese traditional medicine... Vietnamese traditional medicine is made up of ancient health care practices related to the Vietnamese culture" (Hoàng, et al. 1999: 1). Traditional medicine in Vietnam 
This paper has been accepted for publication in health: an interdisciplinary journal for the social study of health, illness and medicine, and the final (edited, revised and typeset) version of this paper will be published in health:; 10(2), April 2006 by Sage Publications Ltd, All rights reserved. (C) Sage Publications Ltd, 2006

comprises of two components: a plant remedy-based form of medicine referred to as thuốc nam (southern medicine) and a Sino-Vietnamese theory and system of healing referred to as thuốc bắc (northern medicine) which includes herbal medicine, acupuncture, massage and exercise techniques. And while Chinese influence is clear, the two Vietnamese scholars Tue Tinh $\left(14^{\text {th }}\right.$ century) and Lãn Ông (18 ${ }^{\text {th }}$ century) are considered the fathers of a form of traditional medicine that was specifically adapted "to the physical and physiological characteristics of the Vietnamese person as well as to the particularities of Vietnamese pathology, which depends on the tropical climate of Vietnam" (Hoàng, et al. 1999: 13).

The Vietnamese case bears many parallels to recent developments in the field of traditional medicine in countries like China, Korea and Ghana, yet there are also certain features that make the Vietnamese case unique, as we will be seeing. Importantly, although each of these countries has followed a path of scientific modernisation in the development of their traditional medicines and each have actively sought to integrate traditional medicine into national health delivery systems, Vietnam's unique history and healthcare system have allowed for an approach that has specifically aimed to build up a "revolutionary movement to bring traditional medicine back to the grassroots level" (Hoàng 2004) not only through its provision by traditional doctors but also by promoting self-sufficiency in the treatment of the most common ailments. In this paper, I will seek to answer the questions of: How has the transformation of traditional medicine from colonial public health evil into postcolonial public health resource been possible in the Vietnamese context? How should we understand this shift? And, what have the specific characteristics of Vietnam's 
This paper has been accepted for publication in health: an interdisciplinary journal for the social study of health, illness and medicine, and the final (edited, revised and typeset) version of this paper will be published in health:; 10(2), April 2006 by Sage Publications Ltd, All rights reserved. (C) Sage Publications Ltd, 2006

ongoing programme to promote the "safe", "effective" and "appropriate" use of traditional medicine in the name of public health been?

To do so, I will begin by briefly outlining some of the major theoretical approaches to doing sociology in this field, as well as present a novel approach which I argue allows me to avoid the dichotomising polemic that is characteristic of much of the research, debate and policy work on traditional medicine. I will then show how traditional medicine in Vietnam was problematised as a hindrance to public health in colonial times (1858-1954) in order to highlight the birth, in 1955, of a Vietnamese strategy to promote the use of traditional herbal medicine. The main part of my analysis will then cover the 50-year period from 1955-2005 and will demonstrate how the products, practitioners and patients of Vietnamese traditional herbal medicine have each been specifically targeted in order to secure its "safe", "effective" and "proper" practice and use.

What follows then is a document-based analysis of contemporary rationalities, strategies and practices that promote the use of traditional herbal medicine in Vietnam. The empirical material - which spans governmental policy papers and strategies, handbooks and guidelines, legislation, scientific research papers, reports prepared by national institutes and associations of traditional medicine as well as documents prepared by international organisations such as the World Health Organization and World Bank (both present and active in the country) - stems from three extended stays in Hanoi, in 1998, 1999 and most recently in the fall of 2004. I have also benefited from numerous conversations with scientists, government 
This paper has been accepted for publication in health: an interdisciplinary journal for the social study of health, illness and medicine, and the final (edited, revised and typeset) version of this paper will be published in health:; 10(2), April 2006 by Sage Publications Ltd, All rights reserved. (C) Sage Publications Ltd, 2006

officials, herbal practitioners and users of herbal medicines during these stays. As part of my conclusion I will reflect on this choice of document-based methodology.

\section{The sociology of TM and CAM}

The past three decades have seen a remarkable growth in sociological and anthropological studies of traditional, complementary and alternative medicines, something not unrelated to the abovementioned global 'boom' or 'revival' in the practice and use of these same therapies. And while it is customary to acknowledge an incredible diversity among such therapies (ranging from homeopathy, herbal medicine, massage, crystallography, acupuncture, reflexology to osteopathy), their shared alterity and/or complementarity in relation to 'modern' or 'bio-' medicine ${ }^{2}$ are nevertheless seen as sufficiently unifying to merit the popular acronyms of TM and

CAM. That is to say, medicines are traditional, complementary or alternative as opposed to biomedicine, which in turn of course begs the question of just what it is that distinguishes these therapies from modern medicine.

Notwithstanding an over-generalising geo-political distinction between the TM of socalled 'developing countries' and the CAM of industrialised countries, it is possible to identify three predominant anthropological and sociological approaches to accounting for the history of traditional, complementary and alternative medicines, all of which emphasise TMCAM/biomedicine dichotomies to varying degrees. The first relates to a personal politics of meaning, cognitive frameworks, values, cultural beliefs, metaphors or identity, suggesting that what TM and CAM have in common is a fundamentally different view of the individual than does biomedicine, as accentuated in whole-person/body or holistic/reductionist dichotomies. This kind of approach is 
This paper has been accepted for publication in health: an interdisciplinary journal for the social study of health, illness and medicine, and the final (edited, revised and typeset) version of this paper will be published in health:; 10(2), April 2006 by Sage Publications Ltd, All rights reserved. (C) Sage Publications Ltd, 2006

often rooted in a classic critique of modernity (not least its medicine) as lifeenfeebling, alienating and dehumanising which is duly contrasted with the vitalising, emancipatory and rehumanising potential of TM and CAM. The point most often argued is that there is more to illness than biology, as active agents seek out (a number of) different cognitive frameworks with which to cope with their diseases, construct suitable identities, negotiate individual life worlds or devise strategies for taking personal responsibility for the improvement and maintenance of their own health and 'quality of life' (see, for example, Cant and Sharma 1996; Coward 1989; Feierman, et al. 1992; Foote-Ardah 2003; Kleinman 1980; O'Connor 1995; Sharma 1992). In these accounts, it is the personalised and holistic nature of TM and CAM that is contrasted to an impersonal and reductionist modern medicine which "does not and cannot provide everything that people need in order to cope with all aspects of the experience of illness, or to meet their desires to achieve or maintain optimal health" (O'Connor 1995: 162).

Another sense in which therapies or treatments have been distinguished as alternative, complementary or traditional relates to the question of their availability through public or private health insurance schemes (primarily in industrialised countries), their place in national public health delivery systems as well as their degree of incorporation into national medical education and research programmes. Such approaches tend to account for the history of TM and CAM in relation to biomedicine in terms of a politics of (self-)interests between rival groups, movements or professions. Crucially, the professionalisation of biomedicine that started in most industrialised countries in the 1800s, quickly spreading to the colonies, is seen as having led to a good century's worth of (self-interested) biomedical 'monopoly', 
This paper has been accepted for publication in health: an interdisciplinary journal for the social study of health, illness and medicine, and the final (edited, revised and typeset) version of this paper will be published in health:; 10(2), April 2006 by Sage Publications Ltd, All rights reserved. (C) Sage Publications Ltd, 2006

'hegemony' or 'domination' that the biomedical profession continues to actively try and protect in the face of challenges stemming from the increasing popularity of traditional, complementary and alternative medicines (cf. Cant and Sharma 1999; Dew 2003; Freidson 1970; Saks 1995). These studies tend to focus on regulatory aspects of TM and CAM, analysing ways in which a demand-driven 'new medical pluralism' is leading to concrete efforts to integrate or 'mainstream' them into national public health delivery systems in both developing and industrialised countries. They also tend to view TM and CAM as "a direct challenge to the authority of the orthodox medical profession" (Sharma 1992: 3), "a potential threat to the biomedical principles underpinning the activities and professional standing of medical orthodoxy" (Saks 1994: 85), or even "a post-modern rejection of the absolute authority of medical science" (Cant and Sharma 2000: 436). Interestingly, a number of studies have highlighted how various forms of traditional and alternative therapy are currently undergoing a kind of professionalisation of their own, involving the creation of practitioner associations, registers, ethical codes of conduct and disciplinary committees, not unlike those found in the biomedical profession (Bodeker and Kronenberg 2002; Last, et al. 1986; Oyebola 1981; Saks 2003; Welsh, et al. 2004).

Finally, a third common form of distinction between TMCAM and biomedicine in sociological and anthropological studies centres around the question of their legitimacy which in turn is dependent on concepts of 'efficacy'. Studies that approach TM and CAM from this point of view often cite a kind of Kuhnian epistemological incommensurability to account for the controversies and antagonisms that surround their practice and use (see Cohen 1998; Tovey, et al. 2004). For example, Thompson, in discussing the growing importance of an 'evidence base' for a therapy's or 
This paper has been accepted for publication in health: an interdisciplinary journal for the social study of health, illness and medicine, and the final (edited, revised and typeset) version of this paper will be published in health:; 10(2), April 2006 by Sage Publications Ltd, All rights reserved. (C) Sage Publications Ltd, 2006

remedy's therapeutic claims, argues that what we must ask of this base is: "What evidence?' and 'Whose evidence?'. These are the very questions that have been and will continue to be highly contested... They are questions that always emerge when incommensurable truth claims meet and the framework for adjudicating these differences eludes us" (Thompson 2002: 61-2). The individualised nature of TM and CAM treatments, some argue, means that they are "not fully measurable through conventional scientific epistemologies" and indeed the fact that TM and CAM treatments are currently being "co-opted" through a process of scientific modernisation may well strip them of their 'real value' (Cohen 1998: 117; cf. also Stone and Matthews 1996). It is also suggested that fundamental differences in underlying theories of health and healing contribute to the epistemological incommensurability, as TM and CAM are seen as supporting the 'natural' capacity of the body to heal itself and re-establish 'balance' as opposed to biomedicine's symptom-busting solutions.

In this paper, I propose a rather different approach to account for the recent history of traditional herbal medicine in Vietnam - not in terms of a politics of cultural meaning, competing (self-)interests or epistemological paradigms, but rather, following Foucault $(1977 ; 1978 ; 1991)$, as a field of problematisation. To do so is to analyse Vietnamese herbal medicine "not from the point of view of politics, but always to ask politics what it has to say about the problems with which it was confronted..., [to] question it about the positions it takes and the reasons it gives for this" (Foucault 1997: 115). For Vietnamese herbal medicine is a problem to which numerous contentious solutions have been proposed over the past many centuries, and rather than pass judgment on these various proposed solutions, it is my intention in this 
This paper has been accepted for publication in health: an interdisciplinary journal for the 10 social study of health, illness and medicine, and the final (edited, revised and typeset) version of this paper will be published in health:; 10(2), April 2006 by Sage Publications Ltd, All rights reserved. (C) Sage Publications Ltd, 2006

paper to illustrate the unavoidably normative grounds that underpin the ongoing elaboration of "safe", "effective" and "proper" ways of using traditional herbal medicine in Vietnam today.

In the following, I will show how public health strategies that aim to modernise traditional herbal medicine on the one hand and to bring it back to the people on the other can usefully be understood in terms of Foucault's concept of 'bio-politics' - as "specific strategies and contestations over problematisations of collective human vitality, morbidity and mortality" (Rabinow and Rose 2003: 3). While it is certainly clear that traditional herbal medicine in Vietnam today has its roots in ancient practices, it is equally clear that in recent times it has come to be appropriated as an object of expert scientific knowledge which has allowed for it to be deployed through national health programmes as a possible solution to very specific and targeted problems of morbidity and ill health in both urban and rural areas of Vietnam. And what I will be arguing is that it is this building up of such expert bodies of knowledge about the most "effective", "safe", and "proper" ways of using and practicing traditional herbal medicine that has been requisite for its recruitment in service of safeguarding and promoting public health - a kind of biopoliticisation of traditional Vietnamese herbal medicine. But first, it is important to understand how medical practices based on ancient Vietnamese traditions were viewed in colonial public health programmes.

\section{Sorcerers and secret remedies}

The role of modern medicine as a 'civilising weapon' in colonial policy and practice throughout the $19^{\text {th }}$ and early $20^{\text {th }}$ centuries is well documented. Whether in large- 
This paper has been accepted for publication in health: an interdisciplinary journal for the 11 social study of health, illness and medicine, and the final (edited, revised and typeset) version of this paper will be published in health:; 10(2), April 2006 by Sage Publications Ltd, All rights reserved. (C) Sage Publications Ltd, 2006

scale tropical hygiene programmes, targeted campaigns to stamp out "witchcraft" or national vaccination initiatives, modern medicine was to play an important role in 'civilising' colonial populations that were considered 'backward', 'primitive' or 'underdeveloped' (see Arnold 1993; Hillier and Jewell 1983; Last, et al. 1986; Stoler 1995). In Vietnam, as Monnais-Rousselot (2003) has shown, the efforts of colonial authorities to "medicalise" French Indochina took hold at the turn of the $20^{\text {th }}$ century with the establishing of a Colonial Health Advisory Council and a Colonial Health Corps of colonial doctors that would set up hospitals and provide medical services under a motto of "Vaccinate, Register and Disinfect". Local or 'auxiliary' doctors were trained at the Hanoi School of Medicine to assist colonial doctors in implementing an Indigenous Medical Assistance programme aimed at preventing epidemic and endemic diseases, especially through hygiene education (ibid.).

The effect of these and similar colonial health care programmes on the practice and use of what is commonly referred to today as Vietnamese traditional medicine was tangible. And although its practice and use was never even close to being abolished, scholars of traditional medicine in Vietnam do suggest that colonial healthcare policies were responsible for "ruthlessly $\mathrm{dr}$ [iving] traditional medicine into stagnation and decline" (Hoàng, et al. 1999: 25-6). This was not in the least because of a largely negative colonial view of Vietnamese traditional medicine as "quackery", made up of "secret remedies" and "superstitious" practices. For example, Monnais-Rousselot quotes a colonial doctor's frustrations when attempting to treat typhoid patients: "Their families... ply them with all sorts of remedies coming from the Chinese quackery; no attention is paid to the cleanliness of the patient. It is only after the failure of Chinese sorcery and witch doctoring that the family brings the patient to the 
This paper has been accepted for publication in health: an interdisciplinary journal for the social study of health, illness and medicine, and the final (edited, revised and typeset) version of this paper will be published in health:; 10(2), April 2006 by Sage Publications Ltd, All rights reserved. (C) Sage Publications Ltd, 2006

hospital" (cited in Monnais-Rousselot 2003: 12-3). Moreover, as a result of it being "ignored by the French-run medical college and scorned by [auxiliary] physicians trained in the European manner who blamed it for its imprecise and anti-scientific knowledge of anatomy and physiology", Hoàng et al. argue that Vietnamese traditional medicine experienced a decline in systematic training and as a result "the number of less than capable traditional physicians or quacks increased" (1999: 25).

What emerges from colonial problematisations of Vietnamese traditional medicine is a general, though not overall (cf. Monnais-Rousselot 2003; Thompson 2004; Tran 2002), rejection of its public health value. In other words, as a consequence of colonial bio-politics in Vietnam, traditional medicine was for the most part marginalised and discouraged by public health programmes which favoured modern pharmaceuticals, hospital services and hygiene education. The theories of healing underlying Vietnamese traditional medicine (closely related to those of traditional Chinese medicine) were dismissed as "unscientific", and even if some of the plants and substances used by Vietnamese herbal practitioners were picked up on by colonial health practitioners for their medicinal and financial value, the sale of "secret remedies" was certainly seen as a threat to public health, especially as these were rarely subject to quality controls and regulation (cf. Monnais-Rousselot 2003). Moreover, there is no question that colonial health authorities in Vietnam, as they did in many other parts of the world, viewed the Vietnamese population as largely incapable of looking after their own health, especially since they were seen as resorting to "superstitions" and "witchcraft" in their quest for healing assistance. In sum, Vietnamese traditional medicine was viewed as much more of a hindrance to ensuring public health than it was a possible support in colonial bio-politics, and as 
This paper has been accepted for publication in health: an interdisciplinary journal for the social study of health, illness and medicine, and the final (edited, revised and typeset) version of this paper will be published in health:; 10(2), April 2006 by Sage Publications Ltd, All rights reserved. (C) Sage Publications Ltd, 2006

already pointed out, its practice and use did suffer as a result in the first half of the $20^{\text {th }}$ century. ${ }^{3}$

\section{The turning point - "We must build our own medicine"}

On the $7^{\text {th }}$ of May $1954,10,000$ French soldiers surrendered to Ho Chi Minh's Viet Minh fighters at Dien Bien Phu, thus putting an end to eight-years of struggle for control of Northern Vietnam between the two. Nine years earlier, Ho Chi Minh had declared the Democratic Republic of Vietnam independent, ultimately igniting Vietnam's 'first war of independence' against French soldiers. Following the departure of the last French soldiers in October 1954, Ho Chi Minh returned to Hanoi to set up a government of the Democratic Republic of Vietnam and it was during these times of nation-building that President Ho Chi Minh was to deliver a famous 1955 speech in which he would echo the words of Chairman Mao in China:

"We must build our own medicine... Our ancestors had rich experience in the treatment of disease using local medications and those of the north [China]. To enlarge the sphere of action of medicine, it is necessary to study means of uniting the effects of oriental remedies with those of Europe" (cited in Hoàng, et al. 1999: 26).

This, it turns out, would be Vietnam's moment of transformation, a moment where Vietnamese traditional medicine was no longer to be discouraged in the name of public health. It was not so much the bio-political goals of protecting and promoting public health in Vietnam that had changed, ${ }^{4}$ yet a space for Vietnamese traditional medicine in securing these was opened up. How should we understand this shift? Should we see it as a return to a more authentic Vietnamese medicine following a 
This paper has been accepted for publication in health: an interdisciplinary journal for the 14 social study of health, illness and medicine, and the final (edited, revised and typeset) version of this paper will be published in health:; 10(2), April 2006 by Sage Publications Ltd, All rights reserved. (C) Sage Publications Ltd, 2006

century of self-interested colonial domination? Or should we understand it in terms of dire shortcomings and limitations of colonial biomedicine in Vietnam? In order to answer these questions and thereby to suggest an account of this shift from marginalising to promoting traditional medicine in the Vietnamese context, I will now take a closer look at what the past fifty years worth of "building our own medicine" in Vietnam has entailed, focusing specifically on herbal medicine.

To begin with, Ho Chi Minh's 1955 call led to the establishing of a network of institutions whose mandate it would be to modernise, standardise and repopularise Vietnamese traditional medicine. The first of these was the National Institute of Traditional Medicine which was opened under the Ministry of Health in 1957 to preserve the legacy of traditional medicine by collecting knowledge about it as well as to promote scientific research into its methods and remedies. In the same year, the first unified National Association of Traditional Practitioners was also formed by active groups of herbalists who had long been incensed by colonial attitudes to their trade (cf. Thompson 2004). This Association was to play an important role in the national objective to collect and preserve knowledge about the practices and remedies of Vietnamese traditional medicine. A few years later in 1961, the Institute of Materia Medica was opened with a mandate to "moderniz[e]... various types of traditional medical formulations" (Vietnam. Institute of Materia Medica. 2004). And in the same year, a Department of Traditional Medicine was opened for the first time in the previously French-run Hanoi Medical College to signal "cooperation between the Traditional Medicine and modern medicine systems in the fields of disease prevention, production of treatment medicine, staff training and scientific research" (Vietnam. Ministry of Health cited in Nguyen 1998). These institutions, associations 
This paper has been accepted for publication in health: an interdisciplinary journal for the social study of health, illness and medicine, and the final (edited, revised and typeset) version of this paper will be published in health:, 10(2), April 2006 by Sage Publications Ltd, All rights reserved. (C) Sage Publications Ltd, 2006

and departments have since proliferated such that by now there are around 40 national or provincial traditional medicine hospitals, ${ }^{5}$ there are over 50 Departments of Traditional Medicine in various provincial hospitals and all seven of Vietnam's medical colleges have a Department of Traditional Medicine. Moreover the National Association of Traditional Practitioners has expanded into a network of associations at the provincial and district levels, ${ }^{6}$ with membership estimates ranging from 20,000 to 34,000 , which in turn is estimated to represent some $50-60 \%$ of all traditional medicine practitioners in Vietnam (cf. Huu and Borton 2003; World Bank 1993). ${ }^{7}$ It is important to note that during this early period of promotion, traditional medicine was used widely in Vietnam's 'second war of independence' against American soldiers (1965-75) to treat burns, wounds and tropical disease, especially since modern medical supplies were often in critical shortage (Hoàng, et al. 1999: 27; Thompson 2004).

In all of these institutions, hospitals and associations, not to mention among the great majority of the population, herbal medicine stands as by far the most important form of Vietnamese traditional medicine. Indeed, herbal medicine has been the cornerstone of Vietnam's national programme to modernise, standardise and repopularise their traditional medicine. In the following, I will address each of these

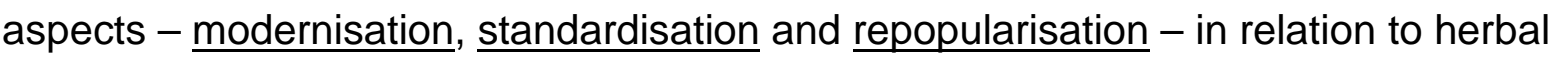
medicine with a view to understanding contemporary forms of problematising herbal medicine, especially as regards the bio-political goals of safeguarding and promoting the health of populations and individuals in Vietnam. No longer necessarily considered 'secret remedies', 'quacks' or 'backward', the products, practitioners and 
This paper has been accepted for publication in health: an interdisciplinary journal for the social study of health, illness and medicine, and the final (edited, revised and typeset) version of this paper will be published in health:, 10(2), April 2006 by Sage Publications Ltd, All rights reserved. (C) Sage Publications Ltd, 2006

patients of herbal medicine nevertheless remain objects of problematisation in today's Vietnam.

\section{Modernising traditional herbal medicines}

What has characterised the push to modernise herbal medicine in Vietnam over the past decades? As a starting point, it has required a comprehensive mapping out exercise of botanical enlightenment, designed to put order into the rich yet, at times, chaotic, unsystematic, unscientific and even unwritten records of herbs and their medicinal uses that have been around for centuries. The key challenges facing the Institute of Materia Medica's scientists were, first of all, that while the experiences of the hundreds and thousands of traditional practitioners around Vietnam were considered invaluable, they were often recorded only sporadically and when done so, names of plants were given in their vernacular forms which varied from region to region and ethnic group to ethnic group. Moreover, correct harvesting information (which has significant bearing on a herb's medicinal potency) was rarely sufficiently noted. And finally, some herbal remedies were nowhere to be found in the otherwise rich archive of Vietnamese herbal records dating back to Tue Tinh's $14^{\text {th }}$ century classic on The Miraculous Medicine of the Southern Country ${ }^{8}$ and Lãn Ông's $18^{\text {th }}$ century Treatise on Medical Knowledge Accumulated by Hải Thuợng, having been "handed down in family circles from father to son, from mother to daughter, [with] secrets... always strictly preserved, particularly among some ethnic minorities" (Bùi 1999: 35). As summarised by Hoàng et al.:

"Under the ancient regime, there was never an official pharmacopoeia for traditional medicine. Medical formulas, uncontrolled, developed in a spontaneous and empirical way" (1999: 27). 

version of this paper will be published in health:; 10(2), April 2006 by Sage Publications Ltd, All rights reserved. (C) Sage Publications Ltd, 2006

Faced with these particular challenges, a strategy unique to the Vietnamese setting was devised, at the heart of which were numerous scientific parties that were sent out on botanizing missions "throughout the country, interviewing traditional practitioners and collecting from the elderly many long-forgotten remedies" (Nguyen 1999: 38). Pharmacist Đỗ Tất Lợi's six-volume series on the Medicinal Plants of Vietnam and their Biochemical Properties (2001), the result of countless journeys and conversations with traditional practitioners over a 20 -year period starting in 1954 , has become a classic of this project, complete with botanical classifications and detailed descriptions of their medicinal uses. The Institute of Materia Medica has also been instrumental in this task, collecting over 8,000 samples, from which 1,850 species have been catalogued according to their vernacular names, scientific names and pharmacological properties (Nguyen 1999: 38). Moreover, the medicinal use of parts of 403 animal species and also of 70 minerals have also been recorded by the Institute of Ecology and Biological Resources (Vietnam Economy 2003a). The pioneer efforts of these many scientists and herbalists were central in ensuring a place for herbal remedies and starting materials in the Vietnamese Pharmacopoeia which consists of two codex, one for modern medicines (published by the Ministry of Health for the first time in 1971) and one for traditional herbal medicines (published for the first time in 1976). Moreover, as a provisional culmination of their work, the Insitute of Materia Medica has "been able to draw up a distribution map of medicinal plants in Vietnam, with approximate estimates of natural reserves" (Nguyen 1999: 38). 
This paper has been accepted for publication in health: an interdisciplinary journal for the social study of health, illness and medicine, and the final (edited, revised and typeset) version of this paper will be published in health:, 10(2), April 2006 by Sage Publications Ltd, All rights reserved. (C) Sage Publications Ltd, 2006

Parallel to this taxonomic drive to collect, collate and classify knowledge about different medicinal plants and traditional herbal formulas, has been a large-scale programme to industrialise a great number of the most used and most relevant herbal remedies in the country such that by today: of the over 10,000 medicines that have been authorised for sale on the Vietnamese market, over 2,000 are classified as herbal medicines (Vietnam. Institute of Drug Quality Control. 2004); the Institute of Materia Medica has developed "thousands" of industrially produced herbal remedies since the 1960s (Bui 2004); and, finally, the harvesting and cultivation of medicinal plants for both export and national use has become a lucrative business (Vietnam Economy 2003b). It was for these reasons that the Ministry of Health, after consultations with the World Health Organization and other national health authorities in the region, approved Decision 371/BYT-QD on the $12^{\text {th }}$ of March 1996, introducing new requirements for the safety and efficacy of herbal medicines (Vietnam. Ministry of Health. 1996). These regulations require that any new industrially produced herbal medicine applying for marketing authorisation must undergo a series of tests to see whether the product meets quality, safety and efficacy standards. Product samples must be sent to the national Institute of Drug Quality Control (opened in 1971 with the publishing of the first Vietnamese Pharmacopoeia) where one out of four quality control laboratories is specifically dedicated to herbal medicines. Laboratory scientists then carry out tests to authenticate (as best possible) declared plant species and composition, chemical analysis, microbial and heavy metal contamination tests, chronic toxicity tests, sub toxicity tests and pharmacological studies. 
This paper has been accepted for publication in health: an interdisciplinary journal for the social study of health, illness and medicine, and the final (edited, revised and typeset) version of this paper will be published in health:; 10(2), April 2006 by Sage Publications Ltd, All rights reserved. (C) Sage Publications Ltd, 2006

One of the major safety concerns to have come out of this process of industrialising herbal medicines in Vietnam has been the deliberate yet illegal lacing of traditional herbal medicines with synthetic medicines for increased potency. Such blends are classed as "counterfeit drugs" in Vietnam and their manufacturers are the target of counterfeit-combating programmes whereby detection of adulteration at the laboratories of the Institute of Drug Quality Control can lead to an immediate product recall by the Ministry of Health as well as fines to the manufacturer (Vietnam. Institute of Drug Quality Control 2003). At the same time, however, the mandate of the IDQC is not limited to industrially manufactured herbal medicines but also includes the "raw" or starting materials of herbal medicine. The IDQC laboratories receive samples from a number of markets for medicinal plants on a weekly basis, the quality of which is checked against 'control profiles' which have been compiled over the years. The IDQC can also, in principle, make unannounced calls on the dispensaries of traditional herbalists in order to control the quality of herbal ingredients being prescribed to patients, especially in terms of pesticide or heavy metal contamination as many of the most popular herbs are by now mass-cultivated using modern agricultural techniques. The unregulated import of significant quantities of medicinal herbs from China and other parts of the region which have not been subject to any quality controls has also been identified as a safety concern (cf. World Bank 1993: 46).

The point here is not that a once 'natural' practice of preparing herbal medicines in Vietnam has now become saturated with rules and regulations with regulators leaving no stone unturned from the urban centres to the remotest of rural villages (if for no other reason than lack of resources), rather it is to demonstrate how 
This paper has been accepted for publication in health: an interdisciplinary journal for the 20 social study of health, illness and medicine, and the final (edited, revised and typeset) version of this paper will be published in health:; 10(2), April 2006 by Sage Publications Ltd, All rights reserved. (C) Sage Publications Ltd, 2006

problematisations of the safety and quality of what are otherwise considered "less aggressive and less toxic" (Bùi 1999: 30) traditional herbal medicines in Vietnam have been dependent on the building up of bodies of expert botanical, pharmacological, phytochemical and pharmacognostic knowledge over the past 50 years or so.

It is these bodies of knowledge that are invariably invoked in the justification of such recent modernising measures as the Ministry of Health's new safety and efficacy requirements for herbal medicines, Good Manufacturing Principles to be followed by herbal medicine producers, anti-counterfeit measures targeting producers that lace their herbs with modern medicines and sustainable cultivation and harvesting programmes to preserve medicinal plant species (see Nguyen 1999). If the safety and quality of industrially produced herbal medicines are going to be ensured and improved in Vietnam, former Director of the Institute of Materia Medica, Prof. Dr. Nguyễn Văn Đàn argues that "as well as traditional methodology we need to utilize new processing methodology with modern facilities and technology and the most advanced methods of quality control" (Nguyen 1999: 48). And so while herbal medicine is widely regarded as an effective and economical means to promoting public health, especially in rural areas where access to modern pharmaceuticals can be limited, industrially-augmented risks of misidentification, contamination and counterfeiting have required a range of new measures to safeguard the public from potentially dangerous "industrially produced" herbal medicinal products. 
This paper has been accepted for publication in health: an interdisciplinary journal for the 21 social study of health, illness and medicine, and the final (edited, revised and typeset) version of this paper will be published in health:; 10(2), April 2006 by Sage Publications Ltd, All rights reserved. (C) Sage Publications Ltd, 2006

\section{Standardising the practice of herbal medicine}

Regulating the practice of traditional herbal medicine has also been an integral part of the Vietnamese government's programme to promote traditional medicine since 1955. As a result, Vietnam is one of the few countries in the world (together with China and Korea) that is seen as having an "integrated approach" to healthcare, with traditional medicine playing a substantial role in medical education, research and practice (World Health Organization 2002: 9). Bùi has suggested that half-a-century into this programme of modernisation, traditional medicine practitioners can today be classed into three different groups: firstly, a 'dying breed' of elder practitioners who have been trained in classical traditional medical techniques with a classical theoretical and philosophical base (thuốc bắc) $;{ }^{9}$ secondly, those who have received training at the traditional medicine faculties of medical colleges or secondary schools of traditional medicine; and finally, 'herb doctors' who have received no formal training but have acquired knowledge and experience through apprenticeships (Bùi 1999: 34-36). ${ }^{10}$ In today's Vietnam, it is by far the latter two groups who provide the majority of herbal medicine treatment, and for this reason it is worth looking at the ways in which their (in)ability as practitioners has come to be problematised as a public health issue over the past decades.

The regulation of the practice of traditional herbal medicine in Vietnam has happened via two specific routes - firstly, by making both modern and traditional medicine compulsory components of medical education and practice in Vietnam (as has happened in China) and, secondly, by the organisation of apprentice-trained 'herb doctors' into national associations as well as the development of a licensing system for these practitioners. Students attending Vietnam's medical colleges are required to 
This paper has been accepted for publication in health: an interdisciplinary journal for the social study of health, illness and medicine, and the final (edited, revised and typeset) version of this paper will be published in health:; 10(2), April 2006 by Sage Publications Ltd, All rights reserved. (C) Sage Publications Ltd, 2006

follow sixteen compulsory courses in traditional medicine (covering classical theory, diagnostics, medical botany and acupuncture) in the first four years of their degrees. Those wishing to do so can then choose to specialise in traditional medicine in their final two years (cf. World Bank 1993: 30). Outside of Vietnam's medical colleges, the Tue Tinh secondary colleges of traditional medicine (the first of which was established in Hanoi in 1971) offer three-year "Assistant Doctor" diplomas which likewise cover both modern and traditional medicine as well as providing further education and 'refresher courses' for practicing medical doctors (World Bank 1993: 31). Traditional medicine graduates from both the medical colleges and the secondary colleges are destined for work in the extensive network of health services found at national, provincial, district and commune levels in Vietnam. ${ }^{11}$ Further to the 40 or so specialised national and provincial hospitals of traditional medicine, the Ministry of Health stipulated by decree in 1976 that each district hospital was to have a department or section specialising in traditional medicine which are often staffed by "Assistant Doctors" although some medical doctors who have specialised in traditional medicine also work at this level. Finally, it is also governmental policy that each commune clinic strive to have at least one staff worker specialised in traditional medicine, responsible also for keeping a garden of medicinal herbs (Hoàng 2004).

Notwithstanding this extensive state-supported healthcare network of hospitals and clinics which the majority of Vietnamese people do have access to through their nearest commune clinic, district hospital or provincial hospital, 'herb doctors' (apprentice-trained rather than college-educated traditional practitioners) continue to play an important role in the delivery of healthcare, especially in rural areas of the country. Even though these 'herb doctors' will often work in cooperation with 
This paper has been accepted for publication in health: an interdisciplinary journal for the 23 social study of health, illness and medicine, and the final (edited, revised and typeset) version of this paper will be published in health:; 10(2), April 2006 by Sage Publications Ltd, All rights reserved. (C) Sage Publications Ltd, 2006

commune clinics and district hospitals, they do constitute a separate category of traditional practitioner, subject to different practice requirements. As already noted, a good share of these practitioners is represented by a network of associations of traditional practitioners at the national, provincial and district levels. These associations have played an important role in the aforementioned efforts to map out medicinal plants and their uses in Vietnam and their members continue to train apprentices and provide medical services to patients via private practices, especially at commune and village levels. However, with the passing of Vietnam's fourth constitution in 1992 according to which it became "strictly forbidden for private organisations and individuals to dispense medical treatment, or to produce and trade in medicaments illegally, thereby damaging the people's health" (Vietnam. 1992: Article 39), the qualifications of private practitioners are increasingly being examined. The constitution has since been followed up by national regulations to govern the private practice of medicine, requiring 'herb doctors' to register their practices with provincial health authorities and to apply for a practicing license which will only be awarded after an evaluation by health authorities, often in cooperation with provincial or district associations of traditional medicine practitioners. ${ }^{12}$ As noted in a report for the World Bank, "a strong thrust of [this] legislation is to ensure that practitioners are properly qualified" (World Bank 1993: 41). This process is for the most part still in its beginnings as by 2003 the Ministry of Health had 'only' licensed 3,715 private practices of traditional medicine (Huu and Borton 2003: 89) which is in sharp contrast to the estimated 20,000 members of the national Association of Traditional Practitioners. 
This paper has been accepted for publication in health: an interdisciplinary journal for the 24 social study of health, illness and medicine, and the final (edited, revised and typeset) version of this paper will be published in health:; 10(2), April 2006 by Sage Publications Ltd, All rights reserved. (C) Sage Publications Ltd, 2006

Yet, whatever the gaps between regulatory intentions and outcomes, it is clearly this group of apprentice-trained traditional practitioners or 'herb doctors' who have come under increasing scrutiny in the past decade or so, especially as regards their training and qualifications. For, although they are often highlighted for the important role that they can and should play in the provision of especially primary health care, a number of public health concerns about their abilities have been raised. For example, the World Health Organization in Vietnam lists as key obstacles that: their explanations can appear "mysterious"; some practitioners are not sufficiently qualified while others overstate their abilities; their lack of knowledge of modern medicine can be harmful to patients; and they tend to keep their 'know-how' secret (World Health Organization 2004b). In light of these kinds of concerns, Bùi has argued that "if traditional practitioners are to play an effective role in health care, it is necessary to advance their professional skills" (Bùi 1999: 33). And although, as already mentioned, this is a process that has only just begun, proposals and initiatives for addressing these concerns are plentiful, including a recent 'crack-down' on traditional medicine establishments by the Ministry of Health (Vietnam News Agency 2004), a World Bank consultant's suggestion that "concerns about qualifications could be offset by increasing on-job training for private practitioners" (World Bank 1993: 42) as well as the WHO's call for "a distance learning programme... in response to the urgent need to upgrade the skills and knowledge of Traditional Medicine doctors working at provincial and district levels" (World Health Organization 1997: 4). The various Traditional Medicine Associations and Secondary Schools of Traditional Medicine have also responded to these concerns by providing training courses and refresher courses for members, for example in the basics of anatomy and physiology (Bùi 1999: 33; Huu and Borton 2003: 61). 
Again, the point to be made is not that an ancient master-apprentice tradition is now becoming saturated by licensing rules and regulations, rather what is evident is that the art or skill of practicing traditional herbal medicine in Vietnam is also in the process of becoming the object of an expert knowledge that is being called upon to determine safety, competency and quality criteria as a means to prevent the "damaging of the people's health". Vietnam has embarked on a normative process, which is only just in its beginnings, to identify what is meant by the terms "proper" and "safe" practice of traditional herbal medicine.

\section{"Re-educating the people"}

What of the users of herbal medicine in Vietnam, the great majority of which continue to live in rural areas, often far away from the Ministries, Associations, Departments and Institutions of traditional medicine that issue decrees, guidelines or training manuals? These are the people who are often self-medicating with herbs not necessarily as a matter of some kind of personal choice but sometimes because access to other medical services is all but non-existent. Nevertheless, while one would perhaps assume that since Vietnam has had such a long history of herbal medicine use its promotion has never been a problem, this is far from being the case, and the popularity and use of traditional herbal medicines has had its peaks and troughs since the battle of Dien Bien Phu in May 1954 (cf. Hoàng 2004; Hoàng, et al. 1999). The period might be roughly divided into three parts with the first three decades up to 1985 characterised by a chronic shortage of modern medicinal supplies as a direct result of trade embargos against Vietnam. As a way to overcome this shortage, the Vietnamese government launched a "revolutionary movement to 
This paper has been accepted for publication in health: an interdisciplinary journal for the social study of health, illness and medicine, and the final (edited, revised and typeset) version of this paper will be published in health:; 10(2), April 2006 by Sage Publications Ltd, All rights reserved. (C) Sage Publications Ltd, 2006

bring traditional medicine back to the grassroots level" (Hoàng 2004), especially since colonial policies had done so much to discourage the use of traditional medicine. Starting in the early 1960s and inspired by China's "barefoot doctors" programme, the National Institute of Traditional Medicine organised a number of training courses aimed at mobilising and training some 2,000 activists who were to return to their districts as focal persons for the promotion of traditional medicine, initially in North Vietnam. The Institute also nominated groups of three to four persons who were then sent out to a number of villages to work with medical staff in the area on ways to promote traditional medicine. Following the reunification of Vietnam in 1976 these efforts were expanded to the rest of the country with the Ministry of Health issuing a decree requiring every district to have a department or institute that provided traditional medical treatment. It is estimated that $40-50 \%$ of all medical treatment being provided at the time was based on traditional medicine, herbal medicine and acupuncture being the most popular therapies (cf. Hoàng 2004; Huu and Borton 2003).

However, when the Vietnamese government embarked on a series of economic reforms starting in 1986, it had a marked impact on the provision and practice of traditional medicine with "many herbal pharmacists and acupuncturists abandon[ing] their practices" (Huu and Borton 2003: 87) mainly because the subsidies they had been receiving from health authorities were rescinded. At the same time, modern drugs were becoming more freely available with trade embargos gradually being lifted. As a result, traditional medicine experienced a period of decline that lasted until about 1992. Since then, the Ministry of Health has led an active campaign to once again "revitalise" or "revive" traditional medicine (this being the third and final 
This paper has been accepted for publication in health: an interdisciplinary journal for the social study of health, illness and medicine, and the final (edited, revised and typeset) version of this paper will be published in health:, 10(2), April 2006 by Sage Publications Ltd, All rights reserved. (C) Sage Publications Ltd, 2006

repopularisation phase of the post-independence period). Important components of this "revival" campaign have been the "Drugs at Home" and "Doctor at Home" programmes of the Ministry of Health (cf. World Bank 1993) as well as a "national policy for traditional medicine through 2010" launched in July 2003 and approved by the Prime Minister in November 2003.

The "Drugs at Home" programme was designed to encourage communal clinics as well as villagers to grow thirty-five species of essential medicinal plants in their gardens which are known for their anti-influenza, anti-inflammatory, anti-dysenteric, anti-rheumatic, anti-tussive, anti-diarrhoeic and emmenagogic properties. Each commune is encouraged to reserve more than half a hectare for such cultivation and the goal is to have about $40 \%$ of patients treated with herbal remedies at communal clinics (Bùi 1999: 30-31). As part of the "Doctor at Home" programme, a book entitled "Herbal Medicines for Families" has been prepared providing users with instructions on how to prepare remedies for some of their most common ailments including diarrhoea, whooping cough, allergies, hormonal imbalance and colitis (cf. Bùi 1999; World Bank 1993). The national policy on traditional medicine through 2010 has set traditional medicine usage targets of $10 \%$ at the central level, $20 \%$ at provincial level, $25 \%$ at the district level and $40 \%$ at the communal level, while also suggesting that sales of traditional medicinal products could be pushed up to $30 \%$ of the domestic pharmaceutical market (Vietnam. Ministry of Health. 2003).

This revitalization effort, spearheaded by the Ministry of Health but involving traditional practitioners, rural hospitals, a number of trained activists as well as the rural populations themselves, has been described as a programme to "re-educate the 

version of this paper will be published in health:; 10(2), April 2006 by Sage Publications Ltd, All rights reserved. (C) Sage Publications Ltd, 2006

local people on the use of herbal remedies and [to] encourage them to grow and use medicinal plants" (Huu and Borton 2003: 67). ${ }^{13}$ In other words, the colonial mission to 'civilise' what were seen as 'backward' and 'superstitious' natives have been replaced by programmes to 're-educate' the Vietnamese people on the use of herbal medicines and to encourage the growth of herbal medicinal plants as a cost-effective way of treating some of the most common ailments in Vietnam, especially in rural areas. There is an important and crucial distinction to be made between the two very contrasting strategies, as colonial programmes definitely tended to objectify Vietnamese individuals as 'inferior' or 'backwards' whereas contemporary programmes view individuals as fully capable partners and resources in the quest to improve public health. "Re-education" is required to the extent that colonial policies were successful in discouraging the use of traditional herbal medicines. At the same time, in Vietnam, as in many other countries, consumers of herbal medicines have become the target of very practical health programmes (such as the "Doctor at Home" programme) which, in the words of the WHO, "promote the proper use of TM/CAM through consumer education/training" (World Health Organization 2004a: x, my emphasis).

\section{Conclusion: quackery transformed}

As has been the case in many African and Asian countries, Vietnam has experienced a tangible traditional medicine 'revival' over the past fifty years. The strategy of scientific modernisation that has played out in Vietnam also bears a number of similarities to what has been happening in many other countries, such as Malaysia and Ghana. But what has made the Vietnamese case relatively unique is the extent to which the practice and use of traditional herbal medicine has been integrated into 
This paper has been accepted for publication in health: an interdisciplinary journal for the social study of health, illness and medicine, and the final (edited, revised and typeset) version of this paper will be published in health:; 10(2), April 2006 by Sage Publications Ltd, All rights reserved. (C) Sage Publications Ltd, 2006

the national public health delivery system and as already pointed out, only China and Korea are considered comparable in this respect. More specifically, there is a strong case for arguing that the efforts to encourage especially those people in more rural areas to become self-sufficient in the traditional herbal treatment of their most common ailments continue to be among the most comprehensive in the world which as noted can be directly linked to a proud history of traditional medicine use dating back many centuries, a prolonged period of postcolonial isolation (due to conflict and embargos) and an impressively far-reaching health delivery network. ${ }^{14}$ Indeed, it must surely stand as one of the great ironies of Vietnam's tragic history that just as modern medicine had been used as a 'civilising weapon' against what were considered 'backward' natives by Vietnam's colonisers, modernising and repopularising traditional medicine in Vietnam became a concrete element of their own grassroots-based efforts to drive these very colonisers out.

What I have demonstrated in this paper is how over the past half-century, Vietnam has experienced a palpable shift in public health strategies from the colonial marginalisation of 'quackery' and 'sorcery' to the postcolonial promotion of a new, responsibilised - that is to say "safe", "proper", "appropriate" - form of Vietnamese traditional medicine. For this reason, there are perhaps some who would make the case that what I have described is but a continuation of the biomedical hegemony of the colonial days in a different guise, that herbal medicine in Vietnam has been 'scientifically colonised' or co-opted, stripped of its original value as a 'natural', ‘Eastern’ or epistemologically distinct form of medicine (notwithstanding that in Vietnam this process has been cast in terms of "building our own medicine"). While I have clearly shown that Vietnamese traditional medicine is currently being 
This paper has been accepted for publication in health: an interdisciplinary journal for the 30 social study of health, illness and medicine, and the final (edited, revised and typeset) version of this paper will be published in health:; 10(2), April 2006 by Sage Publications Ltd, All rights reserved. (C) Sage Publications Ltd, 2006

biopoliticised - i.e. appropriated by expert bodies of knowledge that make authoritative and often contested claims as to what constitute the most 'appropriate', 'effective', 'safe' and 'responsible' ways of practicing and utilising it in the service of public health - I would not argue that this biopoliticisation has come at the cost of a lost 'authenticity' or 'legitimacy'. As it always has been, traditional herbal medicine is under constant revision in Vietnam and it is currently being recast into a form that fits the bio-political aims of safeguarding and promoting public health in Vietnam, which importantly is by no means limited to the maintenance of biological norms of vitality but equally embraces notions of 'quality of life', 'balance' and 'harmony'.

Others might suggest that by choosing a document-based analysis I have neglected the most important aspect of Vietnamese traditional medicine in my account - the subject. These subjects, as numerous anthropological studies have confirmed over the years, are pretty much indifferent to what government regulators or traditional medicine associations consider to be the most 'appropriate' way of using traditional medicine (or any other form of medicine for that matter), they will do as they see fit according to their own particular situations and social contexts as they negotiate their own healing strategies and cognitive frameworks. ${ }^{15}$ What I have shown in no way suggests that individuals are somehow forced into the individual medical choices they make on a day-to-day basis. However, what this article has demonstrated is how the ways in which traditional herbal medicines are gathered, cultivated, harvested, combined and consumed today have become enveloped in a specific mode of problematisation that seeks to answer the bio-political question of how best to safeguard and promote the public health. And in fact, rather than presuppose a subject (as in need of a cognitive healing framework for coping, as guided in his or 
This paper has been accepted for publication in health: an interdisciplinary journal for the 31 social study of health, illness and medicine, and the final (edited, revised and typeset) version of this paper will be published in health:; 10(2), April 2006 by Sage Publications Ltd, All rights reserved. (C) Sage Publications Ltd, 2006

her actions by beliefs, with a capacity for authoritative agency or as a 'whole person'), I would suggest that we can understand the many programmes that seek to promote the responsible and appropriate use of traditional herbal medicines as important components in the contemporary making up and managing of subjectivities in Vietnam.

And finally, I might also be slated for not highlighting the inequalities in resources and relations between modern and traditional practitioners and other practical problems that prevent the 'true' integration of modern and traditional medicine that persist to this day in Vietnam. In many ways, it could be argued, whatever the declared ambitions of 'collaboration' and 'unity', traditional medicine remains subordinate to biomedicine as international organisations, foreign donors as well as Vietnam's own Ministry of Health prioritise biomedicine at the cost of traditional medicine. Such resource inequalities can surely be demonstrated, ${ }^{16}$ but the focus of my paper has been to approach herbal medicine as a field of bio-political problematisation and not in terms of a politics of competing interests between rival groups. What I have shown in this paper is that whatever competing 'interests' there may be, whether implicit or explicit, there is nonetheless a common bio-political mode of problematisation at stake - how best to safeguard and promote the public health. Unequal resources and relations between traditional and modern medicine are considered problems in themselves, not in spite of bio-political public health rationalities, but because of them.

And so, it is in the ways demonstrated in this paper that I suggest the 'quackery' of colonial times has been transformed into the 'traditional medicine' of contemporary Vietnam. The past fifty years of efforts to modernise and responsibilise the products 
This paper has been accepted for publication in health: an interdisciplinary journal for the 32 social study of health, illness and medicine, and the final (edited, revised and typeset) version of this paper will be published in health:; 10(2), April 2006 by Sage Publications Ltd, All rights reserved. (C) Sage Publications Ltd, 2006

and practitioners of herbal medicine underline a relatively new mode of problematisation in which far from all herbal formulas are seen as 'miracle cures' or 'secret remedies' and far from all traditional practitioners are considered 'quacks' or 'sorcerers', but it remains just as clear that the problems of 'inappropriate' and 'dangerous' practice of traditional herbal medicine are here to stay. Focus has been redirected at the contaminated and counterfeit herbal medicines on the one hand, and on the other, at those unlicensed, unregistered, unqualified, untrained or even 'rogue' herbalists that either actively distance themselves from or are oblivious to governmental licensing systems and/or the voluntary codes of practice advocated by practitioner associations. As for the self-medicating patients of herbal medicine, their "proper" cultivation, harvesting and use of herbal medicines has become a concrete site of bio-political problematisation. 
This paper has been accepted for publication in health: an interdisciplinary journal for the 33 social study of health, illness and medicine, and the final (edited, revised and typeset) version of this paper will be published in health:; 10(2), April 2006 by Sage Publications Ltd, All rights reserved. (C) Sage Publications Ltd, 2006

\section{Notes}

${ }^{1}$ See Taylor (2005) for an account of how traditional Chinese medicine became an important element of the national public health policies of the Chinese Communist Party.

${ }^{2}$ In these studies biomedicine is commonly referred to as "the dominant allopathic approach that treats disease as a breakdown to be repaired by direct biochemical and/or surgical intervention" (Saks 1995: 104). I will use the terms 'biomedicine' and 'modern medicine' interchangeably throughout.

${ }^{3}$ Notwithstanding the generally negative climate facing Vietnamese traditional medicine during colonial times (often referred to as a "period of stagnation"), Thompson (2004) has shown how the roots of today's collaborative, rather than competitive, relationship between biomedically trained and traditional practitioners can be traced to the colonial period. Moreover, Guénel (2005) has demonstrated how more than 600 titles published in the 1930-1960 period (most before 1954) are currently catalogued under the heading "Đông Y" (Oriental Medicine) at the National Library in Hanoi.

${ }^{4}$ One can certainly ask the questions of to what extent did colonial authorities work to safeguard and promote the health and well-being of their 'native' populations, whether or not they did this equally in urban and rural areas as well as whether or not they succeeded. What I am maintaining here is that public health goals were nevertheless explicit in colonial health programmes, often justified by arguments that promoting public health would help to increase the productivity of the 'natives' for the benefit of the colony (see Monnais-Rousselot 2002).

${ }^{5}$ The National Institute of Traditional Medicine today goes by the name of the National Hospital of Traditional Medicine.

${ }^{6}$ With an estimated population of over 80 million, Vietnam is today administratively divided into 61 provinces, 500 districts and approximately 8,850 communes.

${ }^{7}$ This means that there are anywhere between 30,000 - 70,000 traditional medicine practitioners in Vietnam which is comparable to the country's corps of ca. 40,000 trained medical doctors (of which 7,800 have specialised in traditional medicine) (cf. United Nations Development Programme 2004; Vietnam Economy 2003a).

8 'Southern' here is in relation to China.

${ }^{9}$ Bui suggests that "nowadays, for reasons of advanced age, few practitioners want to participate in the area of classical medicine, but are dedicated to teaching and treatment in well-organised centres 
This paper has been accepted for publication in health: an interdisciplinary journal for the 34 social study of health, illness and medicine, and the final (edited, revised and typeset) version of this paper will be published in health:; 10(2), April 2006 by Sage Publications Ltd, All rights reserved. (C) Sage Publications Ltd, 2006

where they are able to transfer their valuable experience to younger generations of physicians" (Bùi 1999: 34).

${ }^{10}$ Nguyen (2003: 28) points out that there are also up to 10,000 traditional 'healers' in Vietnam who can be divided into fortune tellers (thay boi), bonzes (thay phap), and witchdoctors (thay phu tuy), but tellingly these kinds of practitioners are invariably excluded from national programmes to promote Vietnamese traditional medicine.

${ }^{11}$ For a country as poor as Vietnam in GDP per capita terms, its far-reaching health delivery system for all its shortcomings and limitations - is often highlighted as commendable (cf. Barrett, et al. 2001). Monnais-Rousselot (2002) has demonstrated the importance of Vietnam's colonial legacy in this respect.

${ }^{12}$ These regulations include the Ministry of Health's "Ordinance on the Practice of Private Medicine and Pharmacy" from 13 October 1993 and more specifically "Circular No.13/1999/TT-BYT guiding the implementation of the ordinance on the practice of private medicine and pharmacy, regarding the traditional medicine and pharmacy" from 6 July 1999.

${ }^{13}$ Interestingly, a survey by the Institute of Traditional Medicine from 1999 found that $85.2 \%$ of respondents could name and describe the medicinal use of at least ten plants (Huu and Borton 2003: 91).

${ }^{14}$ While there is no question that Vietnam's efforts to "bring traditional medicine back to the grassroots level" has been greatly influenced by similar initiatives in China dating back to the Cultural Revolution, the emphasis on self-sufficiency in Vietnam through such initiatives as the "Doctor at Home" and "Drugs at Home" programmes should be understood in terms of Vietnam's unique history. ${ }^{15}$ See, for example, Kleinman (1980), Feierman et al. (1992) and O'Connor (1995) for empirical discussions of patient eclecticism in their choice of healing strategies in the Taiwanese, Southern African and North American contexts respectively. See also Pescosolido's work on how help-seeking strategies are embedded "within systematically structured patterns of network action" (1992: 1126). ${ }^{16}$ For example, a consultant's report for the World Bank concluded that, "at every level of the traditional medicine sector, a lesser level of investment than in modern medicine has led to discrepancies between the quality of facilities, equipment and staff morale in the two sub-sectors" (World Bank 1993: 38). 
This paper has been accepted for publication in health: an interdisciplinary journal for the social 35 study of health, illness and medicine, and the final (edited, revised and typeset) version of this paper will be published in health:; 10(2), April 2006 by Sage Publications Ltd, All rights reserved. (C) Sage Publications Ltd, 2006

\section{References}

Arnold, D. 1993 Colonizing the body : state medicine and epidemic disease in nineteenth-century India, Berkeley: University of California Press.

Barrett, B., Ladinsky, J. and Volk, N. 2001 'Village-based primary health care in the central highlands of Vietnam', Journal of Community Health 26(1): 51-71.

Bodeker, G. and Kronenberg, F. 2002 'A public health agenda for traditional, complementary, and alternative medicine', American Journal of Public Health 92(10): 1582-1591.

Brown, R. E. 1980 'Rockefeller Medicine in China: Professionalism and Imperialism', in R. F. Arnove (ed) Philanthropy and cultural imperialism : the foundations at home and abroad, Boston: G K Hall.

Bùi, C. H. 1999 'Integration of Traditional Medicine Into the Health Care System', in B. C. Hoàng, Đ. T. Phó and N. Huu (eds) Vietnamese Traditional Medicine, Hanoi: The Gioi Publishers.

Bui, T. B. 2004 'Some of the main achievements of the National Institute of Materia Medica' Institute of Materia Medica, Hanoi.

Cant, S. and Sharma, U. 1996 Complementary and alternative medicines : knowledge in practice, London: Free Association.

- 1999 A new medical pluralism? : alternative medicine, doctors, patients and the state, London: UCL Press.

- 2000 'Alternative health practices and systems', in G. L. Albrecht, R. Fitzpatrick and S.

Scrimshaw (eds) Handbook of social studies in health and medicine, London: Sage.

Cohen, M. H. 1998 Complementary \& alternative medicine : legal boundaries and regulatory perspectives, Baltimore ; London: Johns Hopkins University Press.

Coward, R. 1989 The whole truth : the myth of alternative health, London ; Boston: Faber and Faber.

Dew, K. 2003 Borderland practices : regulating alternative therapies in New Zealand, Dunedin, N.Z.: University of Otago Press.

Do, T. L. 2001 Medicinal Plants of Viet Nam and their Biochemical Properties, 10th Edition, Hanoi.

Feierman, S., Janzen, J. M. and Joint Committee on African, S. 1992 The Social basis of health and healing in Africa, Berkeley ; Oxford: University of California Press.

Foote-Ardah, C. E. 2003 'The meaning of complementary and alternative medicine practices among people with HIV in the United States: strategies for managing everyday life', Sociology of Health \& IIIness 25(5): 481-500.

Foucault, M. 1977 Discipline and punish : the birth of the prison, Harmondsworth: Penguin.

- 1978 The history of sexuality, vol. 1, Harmondsworth: Penguin.

- 1991 'Questions of Method', in G. Burchell, Colin Gordon, Peter Miller, and Michel Foucault. (ed)

The Foucault effect : studies in governmentality : with two lectures by Michel Foucault., London:

Harvester Wheatsheaf.

- 1997 'Polemics, politics and problematizations', in P. Rabinow (ed) Ethics : subjectivity and truth, London: Allen Lane.

Freidson, E. L. 1970 Profession of medicine. A study of the sociology of applied knowledge, New York: Dodd, Mead \& Co.

Guénel, A. 2005 'Nationalism and "Vietnamese medicine", 1930-1950' The 11th International Conference on the History of Science in East Asia, Munich, Germany.

Hillier, S. M. and Jewell, J. A. 1983 Health care and traditional medicine in China, 1800-1982, London ; Boston: Routledge \& Kegan Paul.

Hoàng, B. C. 2004 'Promotion of herbal medicine in the rural areas of Vietnam', personal communication with former Director of Institute of Traditional Medicine (1975-95), Hanoi: 4 November 2004.

Hoàng, B. C., Phó, Đ. T. and Huu, N. 1999 Vietnamese Traditional Medicine, Hanoi: The Gioi Publishers.

Hong, C. D. 2001 'Complementary and alternative medicine in Korea: Current status and future prospects', Journal of Alternative and Complementary Medicine 7: S33-S40. 
This paper has been accepted for publication in health: an interdisciplinary journal for the social 36 study of health, illness and medicine, and the final (edited, revised and typeset) version of this paper will be published in health:; 10(2), April 2006 by Sage Publications Ltd, All rights reserved. (C) Sage Publications Ltd, 2006

Huu, N. and Borton, L. 2003 Traditional Medicine : Vietnamese Culture, Hanoi: The Gioi Publishers.

Kaptchuk, T. J. 1983 The web that has no weaver : understanding Chinese medicine, NY: Congdon and Weed.

Kelner, M. and Wellman, B. 2000 Complementary and alternative medicine : challenge and change, Amsterdam: Harwood Academic ; Abingdon : Marston.

Kleinman, A. 1980 Patients and healers in the context of culture: an exploration of the border land between anthropology, medicine, and psychiatry, Berkeley ; London: University of California Press. Last, M., Chavunduka, G. L. and International African Institute. 1986 The Professionalisation of African medicine, Manchester: Manchester University Press in association with the International African Institute.

Lu, G.-d. and Needham, J. 1980 Celestial lancets : a history and rationale of acupuncture and moxa, Cambridge: Cambridge University Press.

Monnais-Rousselot, L. 2002 'Developing Health Care in Indochina : In the Shadow of the Colonial Hospital, 1860 - 1939', in G. Bousquet and P. Brocheux (eds) Vietnam Exposé : French Scholarship on Twentieth-Century Vietnam, Ann Arbor: University of Michigan Press.

- 2003 'Which medications did they trust? The Role of French Colonialism in Vietnamese Attitudes towards pharmaceuticals, 1858-1939' Princeton Workshop in the History of Science: Science Across Cultures - Historical and Philosophical Perspectives, Princeton University, New Jersey: History of Science @ Princeton.

Nguyen, A. 2003 'Cultural and Social Attitudes Towards Mental Illness in Ho Chi Minh City, Vietnam', Stanford Undergraduate Research Journal 2(1): 27-31.

Nguyen, N. K. 1998 'Comparison in Use of the Non-Biomedical Health Care System with the Biomedical System', http://www.healingarts.net/mcnv/kim.html: accessed on 2 December 2004.

Nguyen, V. Đ. 1999 'Traditional Pharmaceutical Activities in Vietnam and their Possible

Development', in B. C. Hoàng, Đ. T. Phó and N. Huu (eds) Vietnamese Traditional Medicine, Hanoi: The Gioi Publishers.

Nigenda, G., Mora-Flores, G., Aldama-Lopez, S. and Orozco-Nunez, E. 2001 'The practice of traditional medicine in Latin America and the Caribbean: The dilemma between regulation and tolerance', Salud Publica De Mexico 43(1): 41-51.

O'Connor, B. B. 1995 Healing traditions : alternative medicine and the health professions, Philadelphia: University of Pennsylvania Press.

Oyebola, D. D. O. 1981 'Professional-Associations, Ethics and Discipline among Yoruba Traditional Healers of Nigeria', Social Science \& Medicine Part B-Medical Anthropology 15(2B): 8792.

Pescosolido, B. A. 1992 'Beyond Rational Choice - the Social Dynamics of How People Seek Help', American Journal of Sociology 97(4): 1096-1138.

Rabinow, P. and Rose, N. 2003 'Thoughts on the concept of bio-power today', Vital Politics: Health, Medicine and Bioeconomics into the 21st century(5-7 September 2003, London School of Economics and Political Science).

Saks, M. P. 1994 'The alternatives to medicine', in J. Gabe, D. Kelleher and G. Williams (eds) Challenging medicine, London: Routledge.

- 1995 Professions and the public interest: medical power, altruism and alternative medicine, London; New York: Routledge.

- 2003 Orthodox and alternative medicine, London: Sage.

Sharma, U. 1992 Complementary medicine today: practitioners and patients, London: Routledge.

Stoler, A. L. 1995 Race and the education of desire : Foucault's History of sexuality and the colonial order of things, Durham: Duke University Press.

Stone, J. and Matthews, J. 1996 Complementary medicine and the law, Oxford New York: Clarendon Press ; Oxford University Press.

Taylor, K. 2005 Chinese medicine in early communist China, 1945-63 : a medicine of revolution, London: Routledge.

Thompson, J. L. 2002 'Which postmodernism? A critical response to 'Therapeutic touch and postmodernism in nursing", Nursing Philosophy 3(1): 58-62. 
This paper has been accepted for publication in health: an interdisciplinary journal for the social 37 study of health, illness and medicine, and the final (edited, revised and typeset) version of this paper will be published in health:; 10(2), April 2006 by Sage Publications Ltd, All rights reserved. (C) Sage Publications Ltd, 2006

Thompson, M. 2004 'Medicine, Nationalism, and Revolution in Vietnam; the Roots of a Medical Collaboration to 1945', East Asian Science, Technology, and Medicine 21.

Tovey, P., Easthope, G. and Adams, J. 2004 The mainstreaming of complementary and alternative medicine : studies in social context, London: Routledge.

Tran, T. L. 2002 'Henriette Bui: The Narrative of Vietnam's First Woman Doctor', in G. Bousquet and P. Brocheux (eds) Vietnam Exposé : French Scholarship on Twentieth-Century Vietnam, Ann Arbor: University of Michigan Press.

Tsey, K. 1997 'Traditional medicine in contemporary Ghana: A public policy analysis', Social Science \& Medicine 45(7): 1065-1074.

United Nations Development Programme 2004 Human Development Report, New York: Oxford University Press.

Unschuld, P. U. 1985 Medicine in China : a history of ideas, Berkeley ; London: University of California Press.

Vietnam Economy 2003a 'The people's medicine needs support' Vietnam Economy, http://www.vneconomy.com.vn/eng/index.php?param=article\&catid=11\&id=031202152029: accessed on 14 June 2004.

- 2003b 'Traditional medicine remedies keep poverty at bay in Lao Cai' Vietnam Economy, http://www.vneconomy.com.vn/eng/index.php?param=article\&catid=11\&id=030710094358: accessed on 14 June 2004.

Vietnam News Agency 2004 'Stricter control over foreign-invested clinics' Hanoi(16 July 2004).

Vietnam. 1992 Constitution, Hanoi: Government of Vietnam.

Vietnam. Institute of Drug Quality Control 2003 'Vien Kiem Nghiem - National Institute of Drug Quality Control', Hanoi: Ministry of Health.

Vietnam. Institute of Drug Quality Control. 2004 'Personal Communication with Director Trinh Van Lau', Hanoi: 21 October 2004.

Vietnam. Institute of Materia Medica. 2004 'Vien Duoc lieu : Institute of Materia Medica', Hanoi: Ministry of Health.

Vietnam. Ministry of Health. 1996 'Decision on the safety and efficacy of herbal medicines'

Decision 371/BYT-QD, Hanoi: Ministry of Health.

- 2003 'National policy on traditional medicine 2010', Hanoi: Ministry of Health.

Welsh, S., Kelner, M., Wellman, B. and Boon, H. 2004 'Moving forward? Complementary and alternative practitioners seeking self-regulation', Sociology of Health \& IIIness 26(2): 216-241.

World Bank 1993 'Traditional Medicine in Vietnam', Consultant's Report prepared by Gerard C.

Bodeker.

World Health Organization 1997 'Workshop on the modernisation of traditional medicine :

mission report in Hanoi, Vietnam, 7-11 April 1997', Manila: WHO Regional Office for the Western

Pacific.

- 2002 Traditional Medicine Strategy 2002-2005, Geneva: World Health Organization.

- 2004a Guidelines on Developing Consumer Information on Proper Use of Traditional,

Complementary and Alternative Medicine, Geneva: WHO.

- 2004b 'Traditional Medicine : Challenges \& Opportunities', Hanoi: WHO Vietnam. 